\title{
Thermal analysis of metal-ceramic bonding using finite element method
}

\author{
S. Gopinath $^{1 *}$, R. Sabarish ${ }^{2}$, R. Sasidharan ${ }^{1}$ \\ ${ }^{1}$ Department of Mechanical Engineering, Tagore Engineering College, Chennai - 127 \\ ${ }^{2}$ Department of Mechanical Engineering, Bharath University, Chennai - 73 \\ *Corresponding author E-mail: gopisiv@gmail.com
}

Copyright $\odot 2014$ S. Gopinath et. al. This is an open access article distributed under the Creative Commons Attribution License, which permits unrestricted use, distribution, and reproduction in any medium, provided the original work is properly cited.

\begin{abstract}
This paper reports a finite element study of effect of bonding strength between metal and ceramic. The bonding strength is evaluated with different processing temperature and holding time. The difference between the coefficients of linear thermal expansion (CTEs) of the metal and ceramic induces thermal stress at the interface. The mismatch thermal stress at the interface region plays an important role in improving bonding strength. Hence, it is essential to evaluate the interface bonding in metal-ceramics joints. The $\mathrm{Al} / \mathrm{SiC}$ bonding was modeled and analyzed using finite element analysis in ANSYS (v.10).
\end{abstract}

Keywords: Bonding Strength, Coefficient of Thermal Expansion, Thermal Stress, Interface, Al/Sic, FEA

\section{Introduction}

The growing interest in aluminum based metal matrix composites could be realized for the past decades because of its superior mechanical and physical properties. The mechanical properties are generally depending on the interface bonding between matrix and reinforcement. It is well known that the function of the interface is to transmit load from matrix to reinforcement due to the large stress gathering capability of the reinforcement and binding property of the matrix material [1]. The formation of interface bond was mainly affected by the factors such as processing temperature and holding time. The different processing temperature and holding time leads to thermal expansion in $\mathrm{Al}$ and Sic Due to their difference in thermal expansion coefficient (CTEs) residual thermal stress will be induced at the interface [2]. This thermal stress will affect the interface bonding between $\mathrm{Al} / \mathrm{SiC}$, which is known as thermal mismatch stress. Metal-ceramic interfacial phenomena controls stress transfer between $\mathrm{Al} / \mathrm{SiC}$ [5]. Generally composite materials with weak interfaces have relatively low strength and stiffness but high resistance to fracture, whereas materials with strong interfaces have high strength and stiffness but are somewhat brittle [6], [7]. S. Sozhamannan et al[1], studies the influence of processing temperature at constant holding time in the interface bonding of Al/Sic The interfacial bonding strength increases with increase in processing temperature due to least formation of interfacial compounds. The structural morphologies of interface in $\mathrm{Al} / \mathrm{SiC}$ interface region. The higher concentration of $\mathrm{Si}$ in the matrix region near the interface alters the interface bonding characteristics of $\mathrm{Al} / \mathrm{Sic}$ the diffusion rate of $\mathrm{Si}$ depends on the functions of temperature and time. The objective of this paper is to analyse the interface residual stress at different holding time and temperature.

\section{Finite element modeling}

One of the most powerful functions of finite element modeling is to generate detailed distributions of stress and strain in the matrix and fiber, which are essential for understanding the mechanical behavior of the composites [4]. The below flow chart shows the finite element modeling procedure. 


\subsection{Analysis procedure}

To find thermal stress between $\mathrm{Al} / \mathrm{SiC}$, coupled-field analysis was used. It couples the two fields (thermal-structural) by applying results from one analysis as loads in another analysis. [ANSYS help].

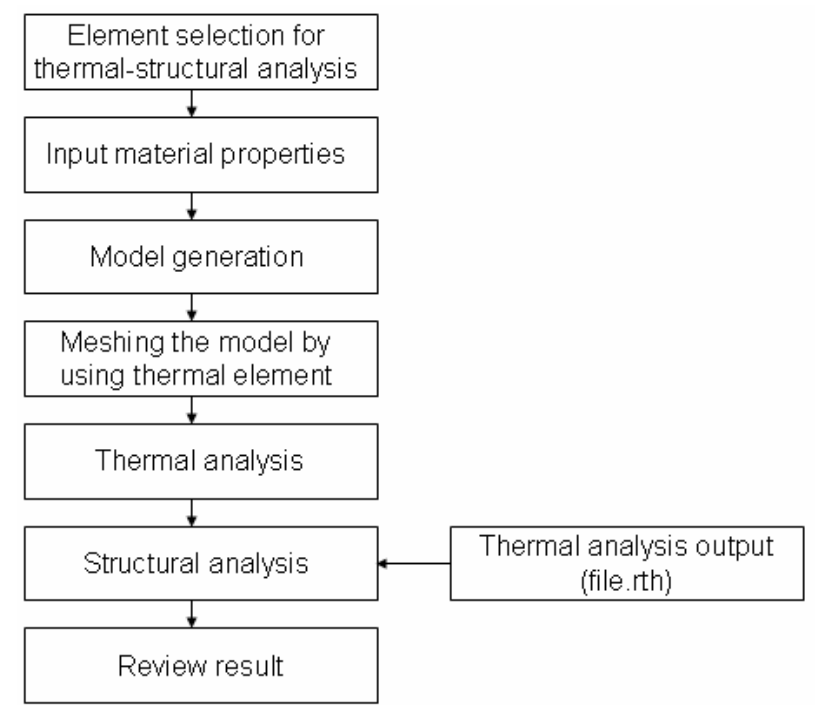

Fig. 1: Flow Chart for Analysis Procedure

\section{Material properties}

\begin{tabular}{cccccr}
\hline Material & $\mathrm{E}(\mathrm{GPa})$ & $\gamma$ & $\mathrm{a}\left({ }^{\mathrm{o}} \mathrm{K}\right)$ & $\mathrm{C}\left(\mathrm{W} / \mathrm{m}^{\circ} \mathrm{K}\right)$ & $\mathrm{c}\left(\mathrm{J} / \mathrm{Kg}{ }^{\circ} \mathrm{K}\right)$ \\
\hline $\mathrm{Al}(\mathrm{LM} 20)$ & 71 & 0.3 & $21 \times 10^{-6}$ & 168 & 902 \\
$\mathrm{SiC}$ & 410 & 0.16 & $4 \times 10^{-6}$ & 120 & 750 \\
\hline
\end{tabular}

\section{Finite element modeling of al-sic and line path diagram}

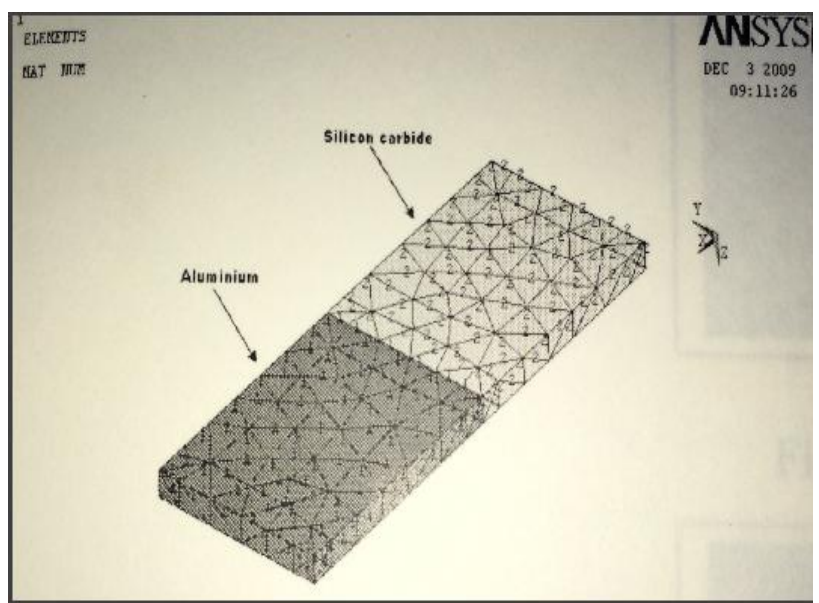

Fig. 2: Al/Sic Mesh Model

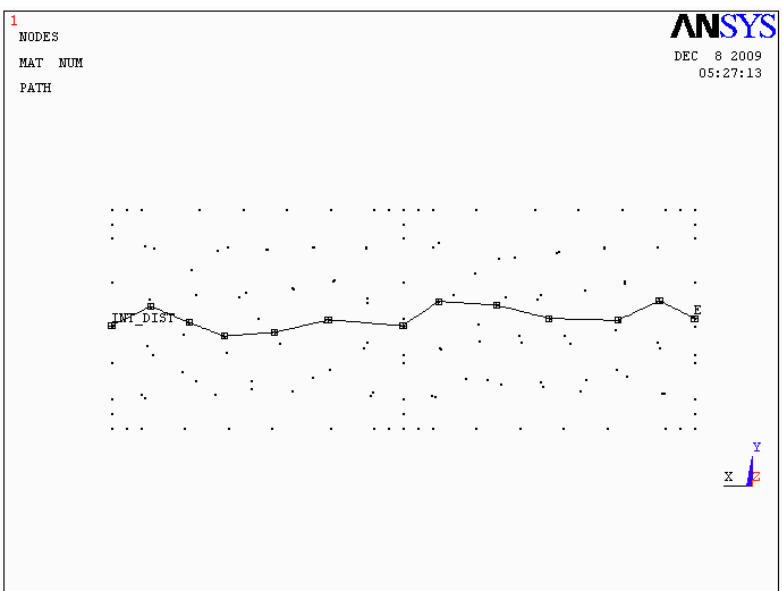

Fig. 3: Line Path Diagram(Nodal solution)

\section{Results and discussions}

\subsection{Thermal stress distribution}

The thermal stress distribution across the interface region is shows in fig. 4 to fig. 6 revealed that the maximum thermal stress were present at the interface region. It is clear evident that the thermal stresses at the interface region increases when increasing processing temperature with holding time. At lower temperature, the thermal stress are low in the range 
from $(-69.717$ to $-169.93 \mathrm{MPa})$. At higher temperature $\left(>800^{\circ} \mathrm{C}\right)$, more thermal stress were accumulated in interface region due to the different thermal expansion value between $\mathrm{SiC}$ and $\mathrm{Al}$ alloy, and also $\mathrm{SiC}$ thermo-dynamically unstable. The presence of higher thermal stress may lead to debonding at the interface and it reduces the load transferring across the interface.

\subsection{Thermal stress distribution diagram}

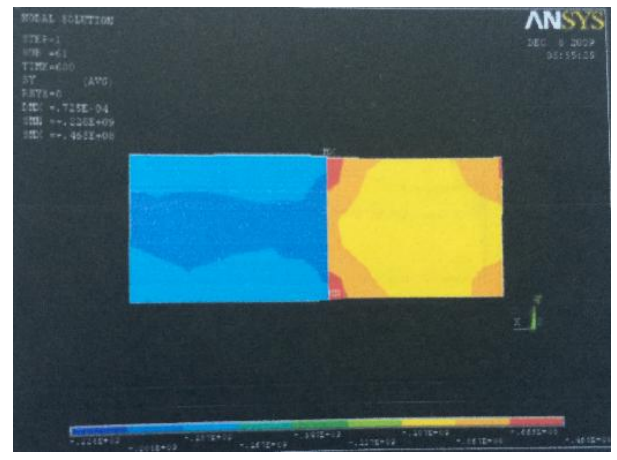

Fig. 4: Thermal Stress Distribution At $10 \mathrm{Min}$

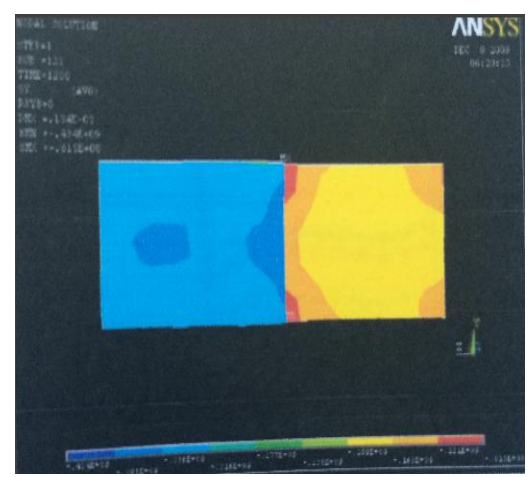

Fig. 5: Thermal Stress Distribution At 20 Min

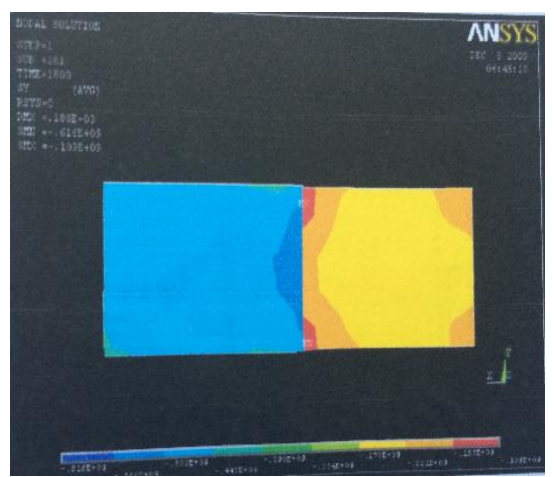

Fig. 6: Thermal Stress at 30 minutes

\subsection{Thermal stresses between $\mathrm{Al}-\mathrm{SiC}$ (x-direction)}
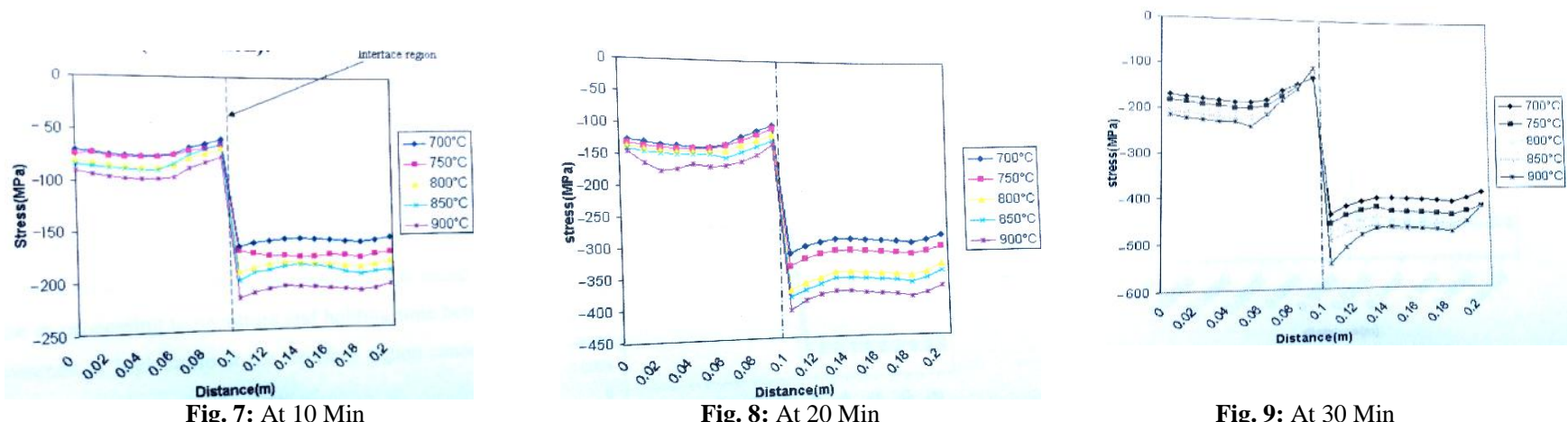

Fig. 8: At 20 Min

Fig. 9: At $30 \mathrm{Min}$

\subsection{Thermal strain distribution diagram}

The thermal strain characteristics are plotted in fig: 10to 12. The strain distribution shows that a maximum thermal strain has been found in the $\mathrm{Al}$ region and also the strain distributions are very low in the SiC side. There is a strain relaxed by the $\mathrm{SiC}$ are transferred to the matrix, which results a matrix are fractured as thermal strain increases. It was found that thermal strains are increased when increase in processing temperature and holding time between Al matrix and $\mathrm{SiC}$ reinforcement. The presence of high strain at the interface region cause the interface bond strength. Since the matrix $(\mathrm{Al})$ and reinforcement $(\mathrm{SiC})$ have different thermal and mechanical properties; they exhibit different thermal strain distributions along the interface region.

\subsection{Thermal strain between Al-SiC (x-direction)}

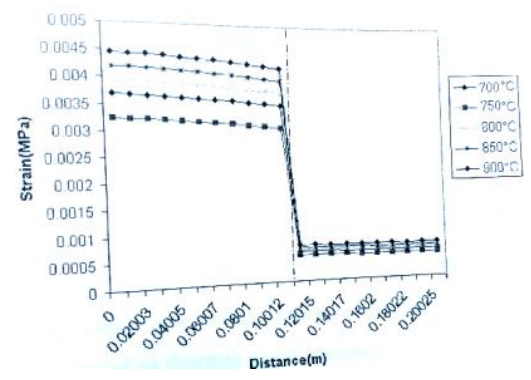

Fig. 10: At $10 \mathrm{Min}$

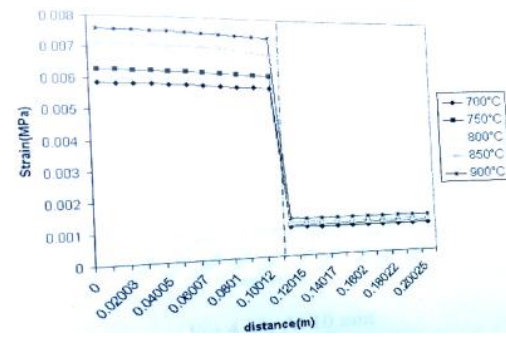

Fig. 11: At $20 \mathrm{Min}$

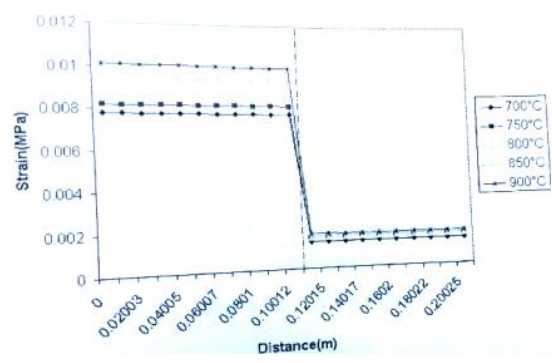

Fig. 12: At $30 \mathrm{Min}$ 


\subsection{Thermal stress distribution at interface region (y-direction)}

The plot shows the thermal stress distribution along the interface region (y-direction).From this plot, it shows the higher thermal stress induced at the corner of the interface region and these phenomena gradually increase with change in temperature and time. The compressive thermal stress act on this interface region between Al and Sic Increase in thermal stress at corner of the interface region induces thermal strain at the reinforcement (SiC) side. There is a strain relaxed by the $\mathrm{SiC}$ are transferred to the matrix which results a matrix are fractured as thermal strain increases.

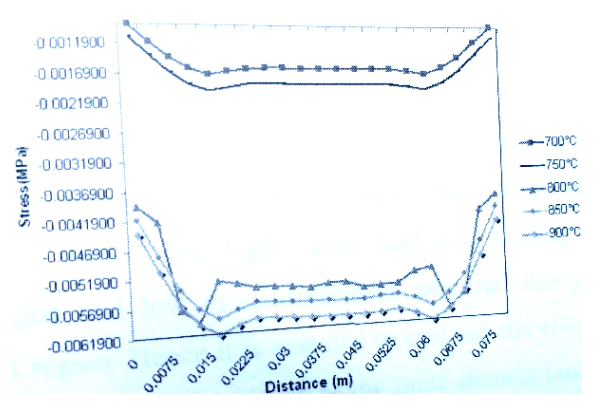

Fig. 13: At $10 \mathrm{Min}$

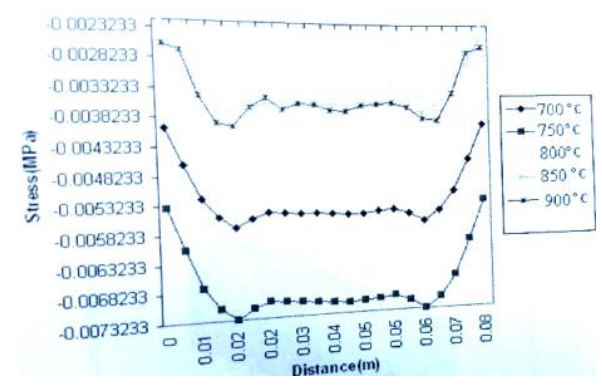

Fig. 14: At $20 \mathrm{Min}$

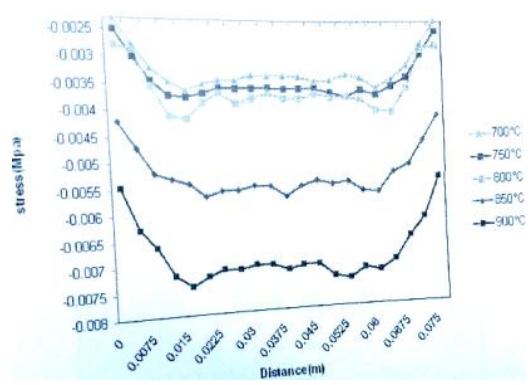

Fig. 15: At 30 Min

\section{Conclusion}

- Increase in various processing temperature with holding time, thermal expansion between $\mathrm{Al}$ and $\mathrm{SiC}$ were increased. This phenomena increase thermal stress at the interface region.

- The higher thermal stresses induce more residual stress at the interface region. This may lead to create deboning between $\mathrm{Al}$ and Sic

- Increase in thermal stress will leads to increase thermal strain at the interface region between $\mathrm{Al}$ and $\mathrm{Sic}$ The higher thermal strain cause interface bonding strength between Al-Sic

- In the interface region, increases in temperature with time, thermal stress were induced at the corner (top and bottom) side.

The presence of higher thermal stress along the interface leads to induce thermal strain in that region, which results matrix fractured as thermal strain increases.

\section{References}

[1] G.G.Sozhamannan, S.BalasivanandhaPrabu, (2009) "Influence of interface compounds on interface bonding characteristics of aluminium and silicon carbide", Materials Characterization, vol 51, pp1044- 5803.

[2] S.BalasivanandhaPrabu, et al (2004) "A Finite Element analysis study of micromechanical interfacial characteristics of metal matrix composites", Journal of Materials Processing Technology, 153-154, pp 992-997.

[3] A. Bendada, et al (2004), "Analysis of thermal contact resistance between polymer and mold in injection molding, Applied Thermal engineering", vol 24, pp 2029-2040.

[4] Vishal Singha, et al (2005), "An experimentally validated thermomechanical model for the prediction of thermal contact conductance", Applied Thermal Engineering, vol 48, pp 5446-5459.

[5] F. Lau a, et al, (1998) "A study of the interfacial heat transfer between an iron casting and a metallic mould", Journal of Materials Processing Technology $7925-296$.

[6] Yongyi Zhu, (1999), “Thermal Contact Development”, Applied Thermal Engineering, vol677, pp 1654- 1232.

[7] A.M. Khounsary, et al, (1997), "Thermal Contact resistance across a copper-silicon interface”, Advanced photon source, vol.604, pp 604394843

[8] A.M.S. Hamouda, M.S.J. Hashrni, (1996) "Mechanical properties of aluminium metal matrix composites under impact loading", Journal of Materials Processing Technology 56 pp 743-756

[9] M. Kemal Apalak, Recep Gunes, (2002) "On non-linear thermal stresses in an adhesively bonded single lap joint", Computers and Structures vol 80, pp 85-98. 